\title{
Understanding Participatory Design of Public Housing Renewal in Singapore: From the Perspectives of History, Strategy and Reflection
}

\begin{abstract}
By Dou Ruiqi
In response to alienation of human-earth relationship and weakened community bonding resulted from rapid urban development since 1960s, a series of participatory design projects have been launched by the Singapore government in cooperation with related grass-roots organizations and researchers, promoting distinctive working model and space prototype. This paper traces the development history of participatory design in Singapore and investigates related public housing renewal projects, so as to conclude operational strategy of Singapore model and to discuss its practical and theoretical significance and enlightenment.
\end{abstract}

\section{Introduction}

\section{Background}

Participatory design, although without single definition due to diverse backgrounds and areas of concern, could be considered as an attitude in creation and management of environments which takes collective intelligence and effort of participants from different backgrounds into consideration. ${ }^{1}$ Its roots lie in the ideals of a participatory democracy where collective decision-making is highly decentralized throughout all sectors of society, so that all individuals learn participatory skills and can effectively participate in various ways in the making of all decisions that affect them. ${ }^{2}$

In terms of housing and community-building, participatory design emerged in 1950s when professionals collaborated with urban poor in developing countries such as Peru, and then developed respectively in the USA and the UK from 1960s to 1970s. Since then, the principles and methods of participatory design have been empirically concluded ${ }^{3}$ with a number of projects practiced in multiple countries. Despite achievements above, most of the projects were bottom-up cases developed by architects or non-profit organizations in low-rise and low-density environment, and there are still several problems to be discussed, for example, the disconnect

*PhD Student, Southeast University, China.

1. H. Sanoff, "Multiple Views of Participatory Design," Focus 8, no. 1 (2011): 11-21.

2. A. T. Carswell, The Encyclopedia of Housing (Thousand Oaks: SAGE Publications, 2012).

3. Sanoff, Community Participation Methods in Design and Planning (Hoboken: John Wiley \& Sons, 1999); N. Wates, The Community Planning Handbook ( $2^{\text {nd }}$ ed.) (London: Routledge, 2014). 
between the initiator's and the public's expectation and the suspicion of participants' impact on the outcomes.

In comparison, the historical and social context is significantly different for Singapore government to carry out participatory design. Gaining independence in 1965, Singapore has transformed from a third world to a modern global city-state with a series of bold urban programmes such as public housing, urban renewal and government land sales, aiming to achieve economic development and to solve housing shortage. ${ }^{5}$ As a result, today over 1 million affordable flats developed by Housing \& Development Board (HDB) provide home for more than $80 \%$ of the residents in Singapore. ${ }^{6}$ Nevertheless, rapidly developed high-rise and highdensity HDB flats also result in side effects in living environment and social life, for instance, alienation of human-earth relationship and weakened community bonding. ${ }^{7}$ In response to issues above, participatory design has been introduced into several programs that encourage residents to participate in community renewal have been launched by HDB with the assistance of People's Association (PA), Town Council (TC), institutions, Residents Community (RC) and other grassroots organizations.

\section{Research Questions}

Initiated by the government and developed in high-rise and high-density environment under rapid urbanization, community renewal in Singapore reflects an alternative model which aims to push on participatory design from bottom-up individual practice to inter-subjective systemic programme. This paper focuses on new features of its organizational support, operational mechanism and design results, which would not only extend the theoretical boundary of participatory design but also provide reference for community renewal under similar condition.

In order to extensively understand Singapore model, three main issues are discussed in this paper: Firstly, why does original bottom-up participatory design become a consensus between the public and the government in Singapore? Secondly, how to carry out participatory design in high-rise and high-density environment with residents widely involved? Thirdly, what is the influence of Singapore model on community building and participatory design research?

4. K. P. Tan, "Public Engagement: The Gap between Rhetoric and Practice," in Ethos (ed.) A. Pang and S. Ng. Singapore: Centre for Governance and Leadership, Civil Service College, 2012.

5. A. F. C. Choe, "The Early Years of Nation-Building: Reflections on Singapore's Urban History," in World Scientific Series on Singapore's 50 Years of Nation-Building, 3-21. Singapore: World Scientific, 2016.

6. Public Housing - A Singapore Icon. [2019-3-8]. https://www.hdb.gov.sg/cs/infoweb/aboutus/our-role/public-housing--a-singapore-icon.

7. L. Hee, C. K. Heng, Transformations of Space: A Retrospective on Public Housing in Singapore Suburban Form: An International Perspective (London: Routledge, 2004), 140-142; K. Stanilov and B. C. Scheer, Suburban Form: An International Perspective (New York: Routledge, 2004), 127-147. 


\section{Methodology}

Facing the issues above, literature review, field research, case study and design practice have been adopted mainly from 3 perspectives:

To begin with, a research on the history of public participation in Singapore is carried out through two clues - the folk background and the official initiatives, so as to find out the cause and driving force of Singapore model.

In the second place, a participatory design project in Hillview @ Elias of Pasir Ris in 2018 is introduced to discuss design strategies in detail. As part of the "Remaking Our Heartland" programme in which residents and stakeholders are actively engaged from the early stages of urban planning to the renewal of community space, this ongoing project could be regarded as a sign that participatory design in Singapore advances from individual experiments to extensive promotion. The author facilitated in field research, process design and design workshop of this project together with professors and students from National University of Singapore (NUS).

At last, based on literature review and case studies, practical effect and experience of Singapore model is concluded and a research framework is proposed to systematically understand participatory design.

\section{Driving Force: History of Public Participation in Singapore}

\section{Folk Background: from "Kampong Spirit" to "Public Participation"}

Although the history of participatory design in modern context is not long since its birth, residents' participation in housing and community building can be traced back as early as to folk houses and spontaneous settlements led by craftsmen, households and their relatives.

Kampong (or kampung), which means Malay village, is the earliest living environment in Singapore and had been around for 400 years before replaced by urban environment during 1960 1980s. ${ }^{8}$ By comparative study between kampong's and modern organizations, operations and spaces, it could be concluded that kampong provides reference for participatory design in the following three perspectives:

Firstly, in terms of organizational support, management of daily affairs and construction of houses and infrastructure were mainly self-organized by the villagers, while issues such as water supply, markets and building inspectorate had long been administered by the government departments (e.g. Rural Board of colonial government from 1909-1958). Under this background, informal leaders worked as the communication channels between the residents and the government, which promoted the development of early grass-roots organizations.

Secondly, in terms of operation methods, gotong royong (mutual aid in Malay) is the basic way to create and maintain living environment, which helped

8. K. F. Tang, Kampong Days: Village Life and Times in Singapore Revisited (Singapore: National Archives, 1993), 10. 
to develop a volunteer culture. For example, villagers' relatives and their neighbors engaged in building houses (Figure 1) and managing security work collaboratively.

Thirdly, in terms of space, porotype of participatory planning and common space could be viewed in Kampong: residents' own houses usually face to others with windows open on all sides, so as to ensure security and to improve ventilation; Anjungs (front porch in Malay, Figure 1) and courtyard were kept as semi-public space for communication.

Even though geographical kampong has disappeared, kampong spirit drew more attention from both the public and the government due to the facts that racial conflict occurred occasionally in urban area and high-density living environment had affected residents' social life and mental health after massive resettlement. ${ }^{9}$ Thus, a consensus between the public and the government is reached, which became the internal driving force to promote participatory design: kampong spirit is not only nostalgia to remember the past and to criticize current situation, but also a political view to seek national identity and to carry out volunteer work.
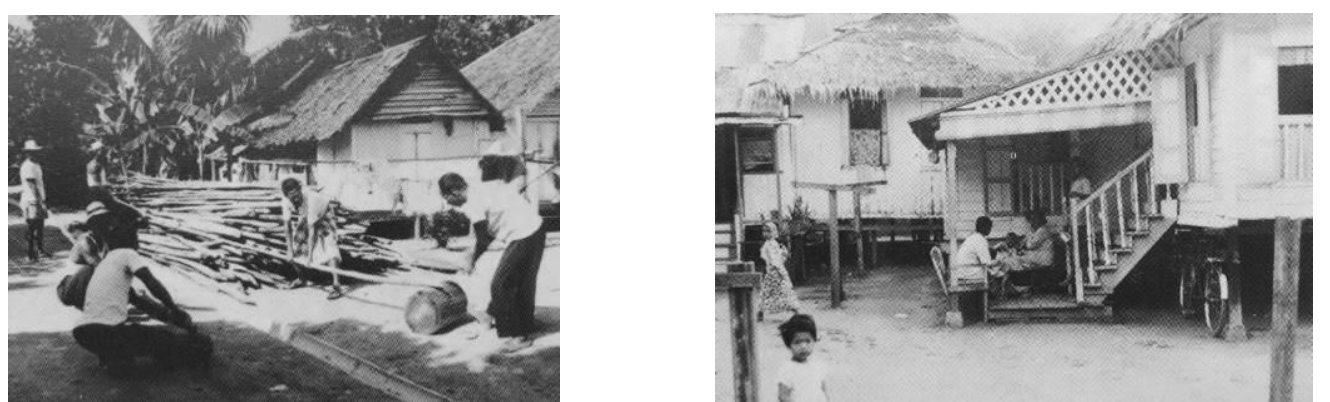

Figure 1. Collaborative Housing Construction in Kampong in 1950s (Left) and Anjungs as Social Place in Malay House (Right)

Source: Tang, Kampong Days: Village Life and Times in Singapore Revisited (Singapore: National Archives, 1993), 21-22.

\section{Official Initiatives: from "Inform" to "Empower"}

Neighbourhood relationship and related space innovation have been concerned from the beginning of public housing construction in Singapore. HDB was established in 1960 to clear squatters and slums and to resettle residents. In the same year PA was founded to manage neighbourhood grassroots communities and social organizations. In 1966, sample household survey, which has been continuously carried out every five years until now, was firstly held to collect social and economic data for future planning by questionnaire. With the efforts above and due to lack of community cohesion and shared facilities, the form of HDB housing has been changed in the aspects of both urban planning and architecture design: from "prototype model" (town-neighbourhood structure, each neighbourhood serves 6,000 households) in the 1970s to "structural model" (townneighbourhood-precinct structure, each precinct serves $400-800$ households) in the

9. R. Hassan, Families in Flats: A Study of Low-Income Families in Public Housing (Singapore: Singapore University Press, 1977). 
1980s (Figure 2), ${ }^{10}$ and from common corridor designed to enhance neighbourhood relationship on the same floor in the 1950s to void deck in the 1970s - overhead space at the bottom designed to hold activities such as weddings, funerals, elections and residents' daily communication. ${ }^{11}$ Although decision-making in planning and development as well as management of public housing is still highly centralized by the HDB, Town councils established in 1988 has taken charge of maintaining the common areas of HDB flats and estates, decentralising and localising the management and introducing new public housing programme. ${ }^{12}$ These developments provide management and space foundation for participatory design in housing renewal project.

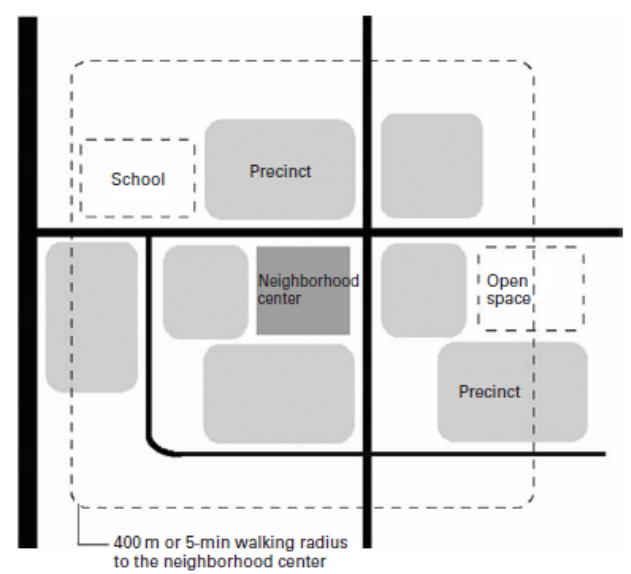

Figure 2. Neighbourhood Diagram in 1983

Source: Stanilov and Scheer, Suburban Form: An International Perspective, 2004, 133.

With joint efforts of the government and the public, residents' participation in HDB housing renewal has increased step by step, which could be explained by The International Association for Public Participation's the 5-degree classification (from low to high) of: inform, consult, participation, collaborate, and empower. ${ }^{13}$ The Main Upgrading Programme(MUP), in which residents could only get informed and give feedback, was launched in 1990 to upgrade physical environment of old HDB estate before replaced by Home Improvement Programme (HIP) in 2007. The Neighbourhood Renewal Programme (NRP), implemented by TC since 2007, gathering residents' feedback by diverse methods such as Town Hall Meetings, dialogue sessions, block parties and miniexhibitions, and would only carries out a project with more than $3 / 4$ of the

10. Hee and Heng, Transformations of Space: A Retrospective on Public Housing in Singapore, 2004; Stanilov and Scheer, Suburban Form: An International Perspective, 2004.

11. S. Cairns, J. J. Jacobs, J. Yingying, R. Padawangi, S. Siddique, E. Tan, "Singapore's Void Decks," in Public Space in Urban Asia, 80-89. World Scientific Publishing Co. Pte. Ltd., 2014; W. S. W. Lim, Public Space in Urban Asia (Singapore: World Scientific Publishing Co., 2014), 80-89.

12. I. S. Cho, B. Križnik, Community-Based Urban Development Evolving Urban Paradigms in Singapore and Seoul (Singapore: Springer Singapore, 2017), 60-66.

13. IAP2's Public Participation Spectrum (Louisville: International Association for Public Participation, 2014). 
community owners' agreement. ${ }^{14}$ Later in 2012 and 2013, Over 2,700 households in Bukit Panjang and 1000 residents in Tampines were encouraged to participate in site selection, program planning and design of community space in "Building Our Neighbourhood Dreams" (BOND!) in 2012 and "Hello Neighbour!" in 2014 by means of survey, seminar and workshop, which marks a further step in HDB community renewal from state-led to residents-driven. Phase 3 of Remaking Our Heartland (2015 ) carried out in Toa Payoh, Woodlands and Pasir Ris invited more residents and stakeholders to participate in Focus Group Discussions in the early stages of the rejuvenation planning, and extensively promoted participatory design of common space in more HDB communities.

\section{Development Strategies: based on a Case Study in Hillview @ Elias}

Participatory design project carried out in Hillview @ Elias of Pasir Ris in 2018 is taken as an example in this section. Based on a seamless "community mall network", the participatory planning result of Remaking Our Heartland programme, this project aims to upgrade public space in a three-block, 2000 households precinct so as to activate adjacent social spaces, which reflects the following three strategies of participatory design in Singapore.

\section{Organizational Strategies}

The operation of participatory design is based on an intersubjective structure (Figure 3) consisting of four groups: the government (HDB, PA and TC), professionals (researchers and students from National University of Singapore and architects from HDB), grassroots organizations (RC and convened volunteers) and residents. The Project Working Committee (PWC), set up by HDB, PA, TC and representatives from $\mathrm{RC}$, is in charge of communication with each group, financial allocation and supervision. Teachers and students majoring in architecture works as facilitators to carry out field research and to design the process instead of the concrete environment, ensuring that the residents get command of the basic skills to form and present their design concepts. Architects from HDB and professional construction team would deal with technical issues after design workshop. Grassroots organizations and volunteers work as link of the residents, the government and the professionals, interpreting ideas of different group, gathering feedback and offering service in special events during the design process. The resident group, including volunteers in design workshop and respondents in field research, reflects living condition, cultural environment and neighbourhood relationship and works as user, designer and evaluator during the project. 2017).

14. Neighbourhood Renewal Programme - NRP (Singapore: Housing \& Development Board, 


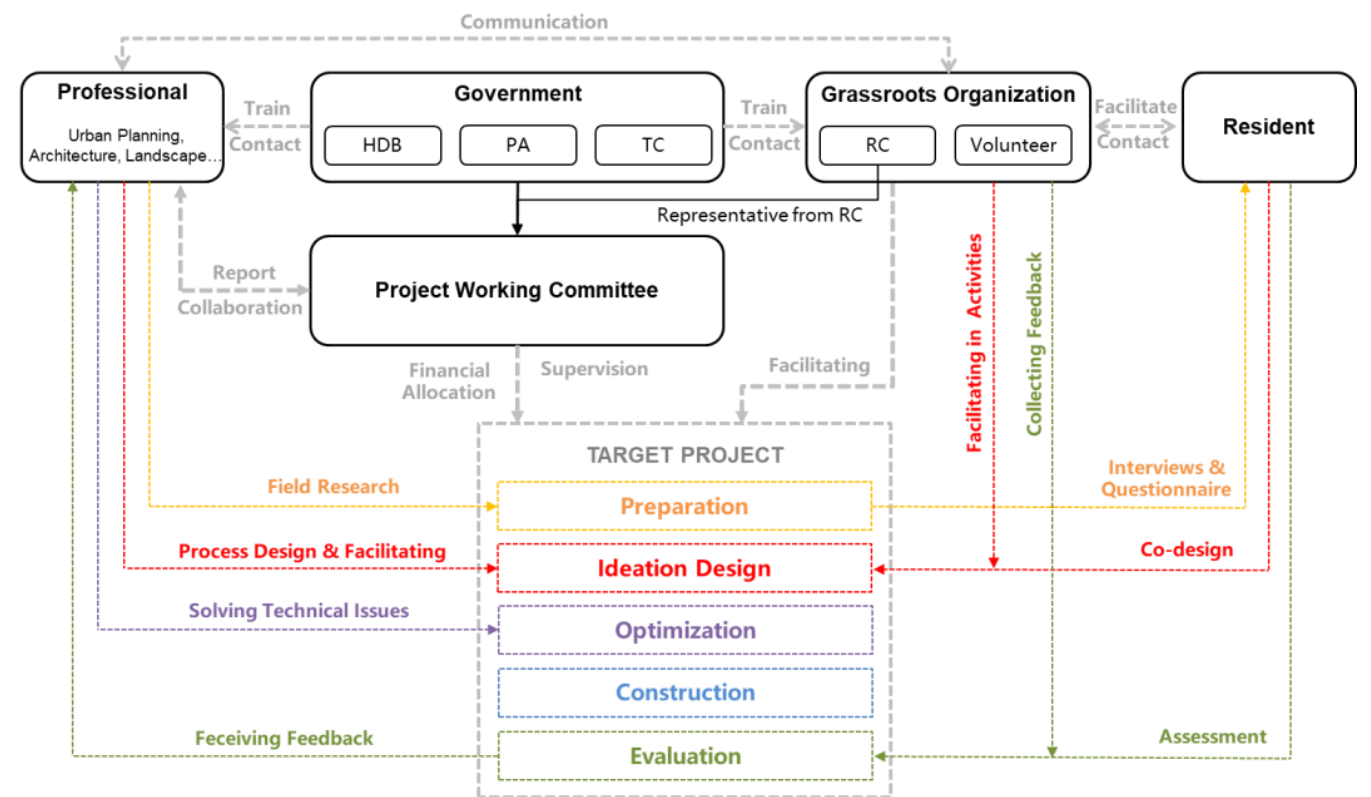

Figure 3. Organizational Structure of Hillview @ Elias Project Source: Drawn by the Author.

In Figure 3 is shown the organizational structure above, the roles of professionals and residents with the help of volunteers, the government and grassroots organizations. The professionals get trained on facilitation model, such as "4D Model" - Determine Requirements, Design the Session, Deliver/Debrief the Session and Discover New Leaning, cultivating awareness in space, process, outcome and time. ${ }^{15}$ As the resident group is generally not a fixed crowd due to time constraint and willingness to participate, informal leaders such as initiator of a project, serviceman in RC or residents with strong leadership would be more likely to participate in the whole process and play an important part in understanding local context and establishing common interest. The other residents, according to field research, tend to participate only if they understand that the project directly benefits them.

Initiated by the government, the way to achieve mutual understanding among different groups is to set a relatively broad target and then to reach a consensus gradually in terms of social capital rather than economic interest. Thus, a participatory design process should be carefully designed and modified flexibly.

\section{Process Strategies}

The 10-week design process is co-formulated by HDB and NUS and adjusted according to residents' feedback, which could be divided into three main stages: Sensing, Pop-up and Ideation Workshop (Table 1).

15. P. Naidu and J. Lua, Spot on Facilitation ( $2^{\text {nd }}$ ed.) (Singapore: Candid Creation Publishing, 2015): 25-114. 
Table 1. Workflow of the Hillview@Elias Project in 2018

\begin{tabular}{|c|c|c|c|c|}
\hline Graphics & Cost & Date & & Activity \\
\hline \multirow{5}{*}{ Sensing } & \multirow{8}{*}{$200 \$$} & & Preparation & \multirow{2}{*}{$\begin{array}{l}\text { Field research methods \& Pop- } \\
\text { up plan }\end{array}$} \\
\hline & & 1.24 & Submit to PWC & \\
\hline & & 1.27 & Field Research & Observation \& Interview \\
\hline & & 2.2 & Report to PWC & Refined Pop-up plan \\
\hline & & 2.5 & Submit to PWC & Research result \& Budget \\
\hline \multirow{3}{*}{ Pop-up } & & 2.10 & Pop-up & Collect residents' concern \\
\hline & & 2.23 & Report to PWC & \multirow{2}{*}{$\begin{array}{l}\text { Pop-up result, Data analysis \& } \\
\text { Site Selection }\end{array}$} \\
\hline & & 3.5 & Submit to PWC & \\
\hline \multirow{6}{*}{$\begin{array}{l}\text { Ideation } \\
\text { Workshop }\end{array}$} & \multirow{6}{*}{$1000 \$$} & 7 & Preparation & \multirow{2}{*}{ Workshop process plan } \\
\hline & & 3.9 & Seminar & \\
\hline & & 3.12 & Submit to PWC & Workflow \& Outcome form \\
\hline & & 3.19 & Submit to PWC & Refined workshop plan \\
\hline & & 4.1 & Workshop & Co-design ideation project \\
\hline & & 4.6 & Seminar & Design result \& Comment \\
\hline
\end{tabular}

Source: Co- Formulated by HDB and NUS.

In Sensing, the designers carried out field research with the methods of site observation and on-street interview, in order to experience local daily life, map important and problematic public places and pathways (Figure 4), build relationships with informal leaders and local connectors, and locate possible sites for intervention. Site observation reveals well distributed educational and sports facilities, self-built gardens, unutilized void decks and blurring boundaries between public and private space in residents' daily life (Figure 5). Informal interviews, on the other hand, reflect locals' evaluation on amenities (convenient but insufficient, not bicycle friendly), shared spaces (quiet, dirty void decks, smokers), activities (not enough) and kampong spirit (friendly, limited interaction, unawareness in younger generation), and give suggestions on possibilities solutions. The outcome of Sensing includes (Figure 6): a new route was proposed for the Community Mall Network according to observation of cyclists and pedestrians; 2 venues were recommended to the PWC to choose the pop-up spot according to human traffic on Saturday morning; several facilities and activities were summarized as image reference according to the interview. 


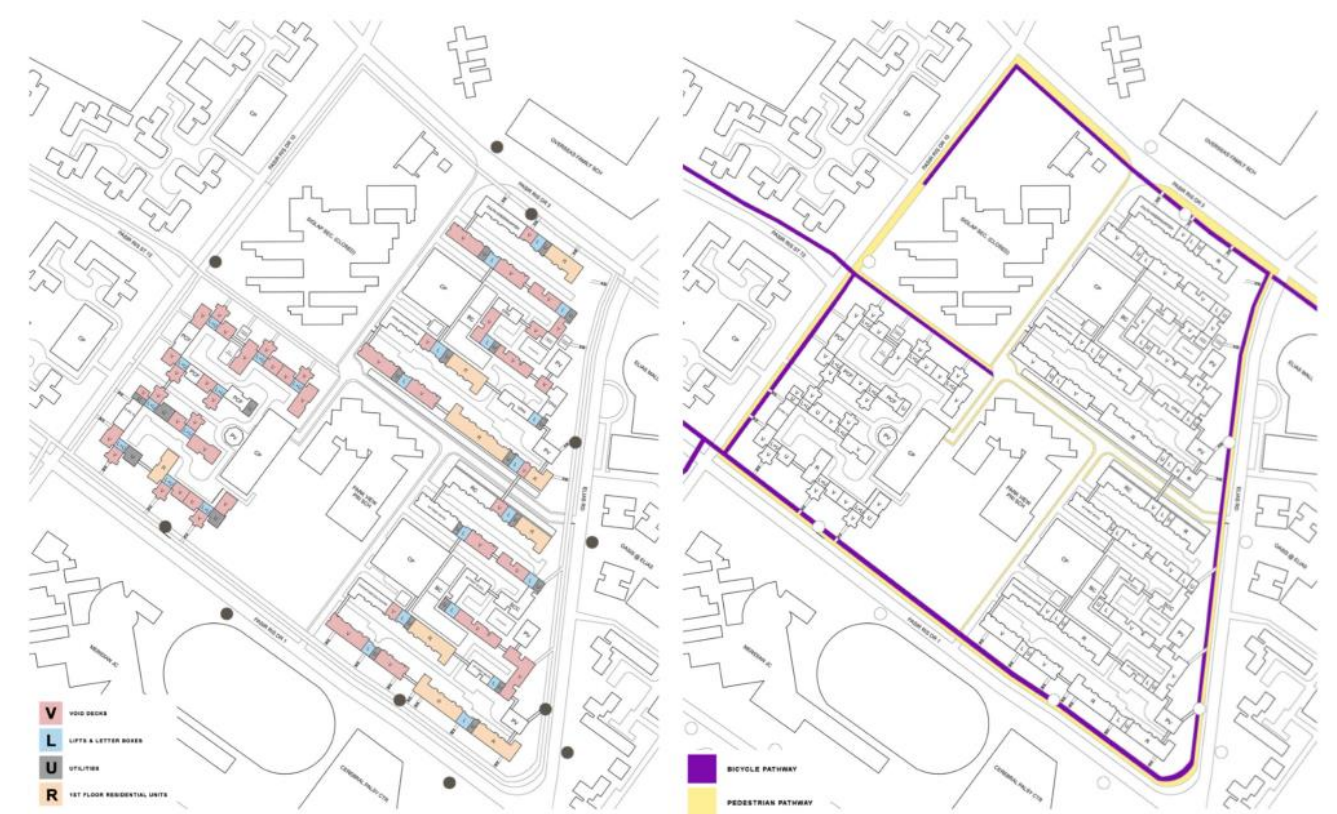

Figure 4. Current Space Classification (Left) and Pathways (Right)

Source: Diagrams Drawn by the Design Team from NUS.
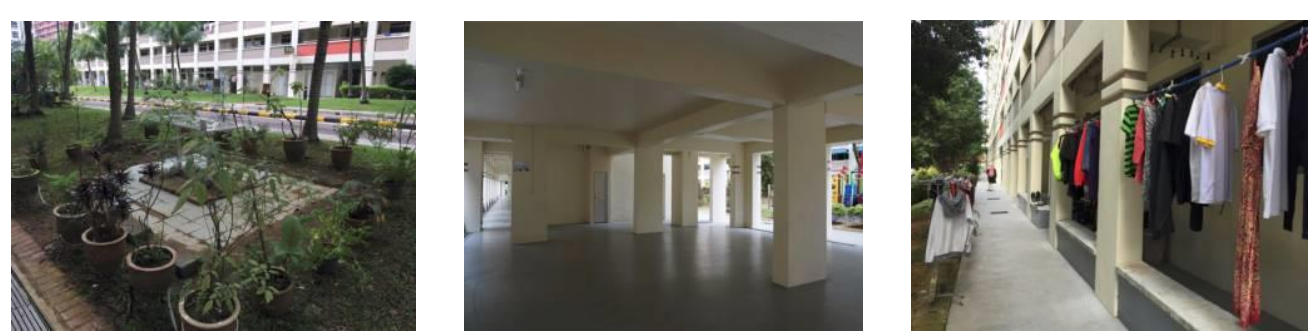

Figure 5. Self-Built Gardens (Left), Unutilized Void Decks (Middle) and Blurring Boundaries (Right)

Source: Photos Taken by the Author.

In Pop-up, the Meeting diversifies participation by going to the people with temporary outdoor booths (such as vehicles, boards, tables and decorations), so as to engage communities with flexible civic encounters that appeal to residents and accommodate their needs. ${ }^{16}$ Pop-up in Hillview @ Elias project was located in the first proposed venue because of greater diversity age group, and was carried out by 4 professionals and 3 volunteers (Figure 7), which lasted for 3 hours on Saturday morning. The professionals assisted residents to pin up their walking and cycling routes at one booth and discussed their facilities and activities at another two, while the volunteers worked as "pullers" to attract pedestrians and helped to collect the basic data of the participants. After this stage, the participants demographics and their preference for the type and location of facilities and activities were analyzed and 2 sites (pathway \& void decks along blk632-634, void deck@blk650) were selected for the Ideation Workshop (Figure 8).

16. D. de la Peña, D. Jones Allen, R. T. Hester Jr., J. Hou, L. L. Lawson, M. J. McNally, Design as Democracy: Techniques for Collective Creativity (Washington, DC: Island Press, 2017), 68-71. 

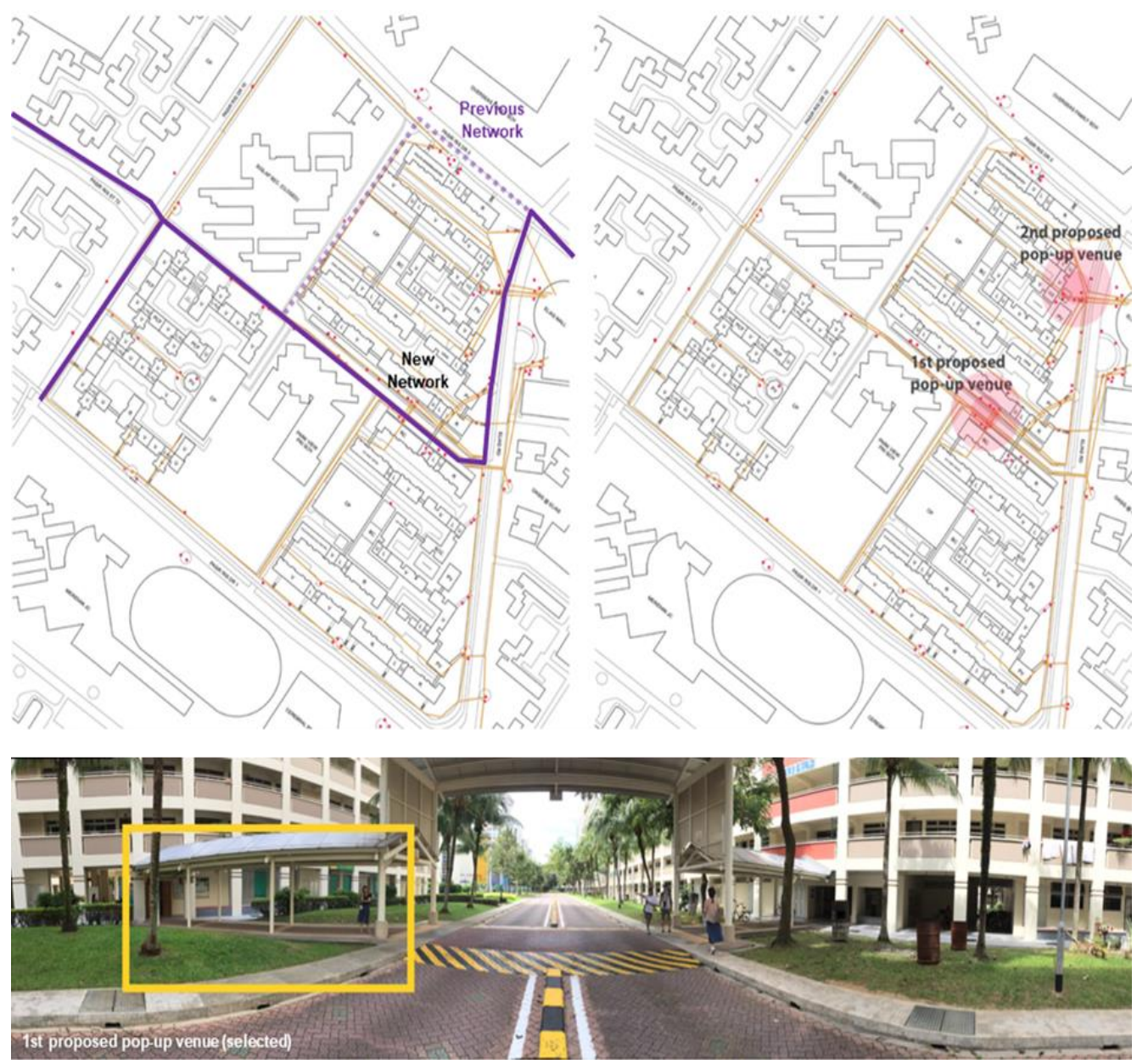

Figure 6. Adjusted Community Mall Network and Proposed Pop-up Venue Source: Diagrams Drawn by the Design Team from NUS and Photos Taken by the Author.
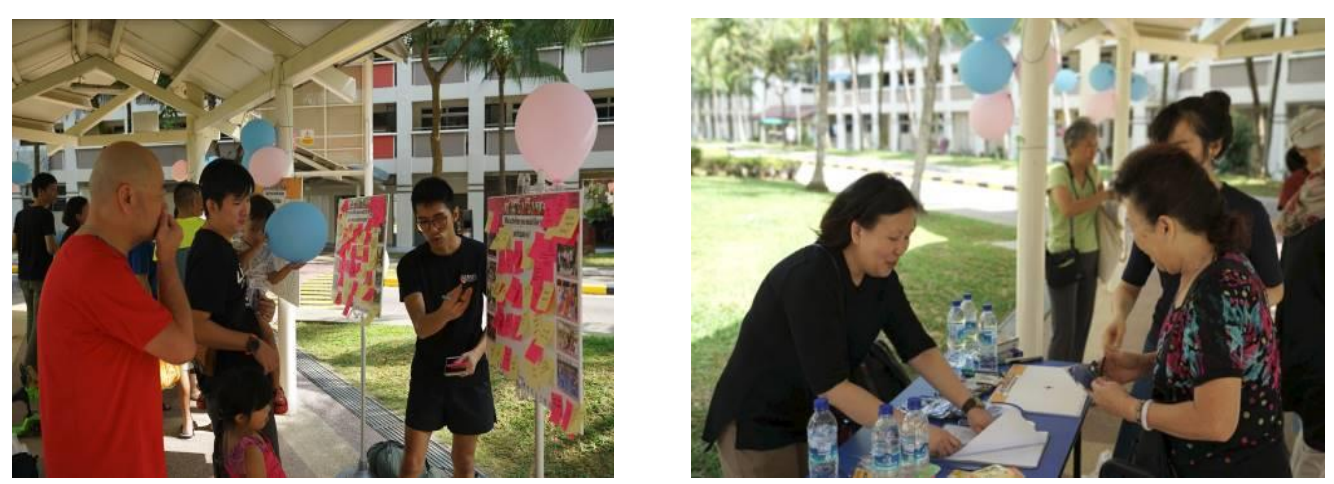

Figure 7. Professionals' (Left) and Volunteers' (Right) Engagement in Pop-up Source: Photos Taken by the Author. 

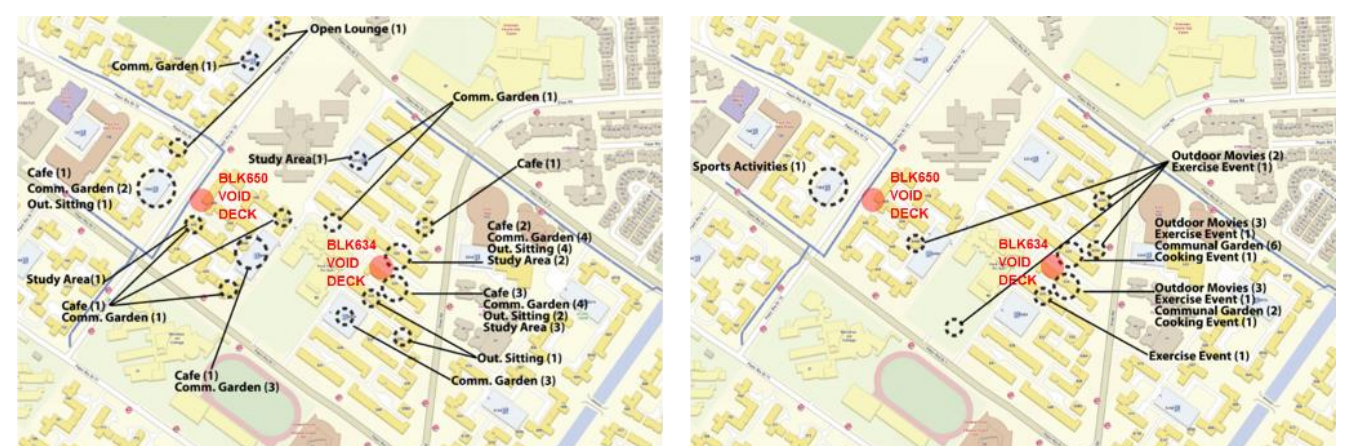

Figure 8. Residents' Preference on Facilities (Left) and Activities (Right) and 2 Sites Selected for the Ideation Workshop

Source: Diagrams Drawn by the Design Team from NUS.

In the Ideation Workshop, all the four groups of participants gathered together in one meeting room, facing the challenge that non-professionals should get the design results within 2.5 hours. The process (Figure 9) is divided into 7 stages and the duration of each activity was taken note of by the co-facilitators. 4 and 7 residents selected by the PWC were appointed to carry out design of 2 sites with assistance of 2 professionals and 1 volunteer respectively. After All the participants were briefed by the chief facilitator, the first part of the workshop was to gather feedbacks regarding the usability \& identity of proposed Community Mall Network, and then they would envision the space based on the pop-up results. Later on, pictures of the current state of the space were shown to the residents to address any possible limitations regarding their proposed envisioned statement. The end of the first half was cross table sharing to address concerns or questions, so as to reach design briefs of each site. Then, the participants were given materials to visualize their own design both in $2 \mathrm{D}$ and $3 \mathrm{D}$, and finally the 2 groups gathered once again to share their design outcomes and ideas.

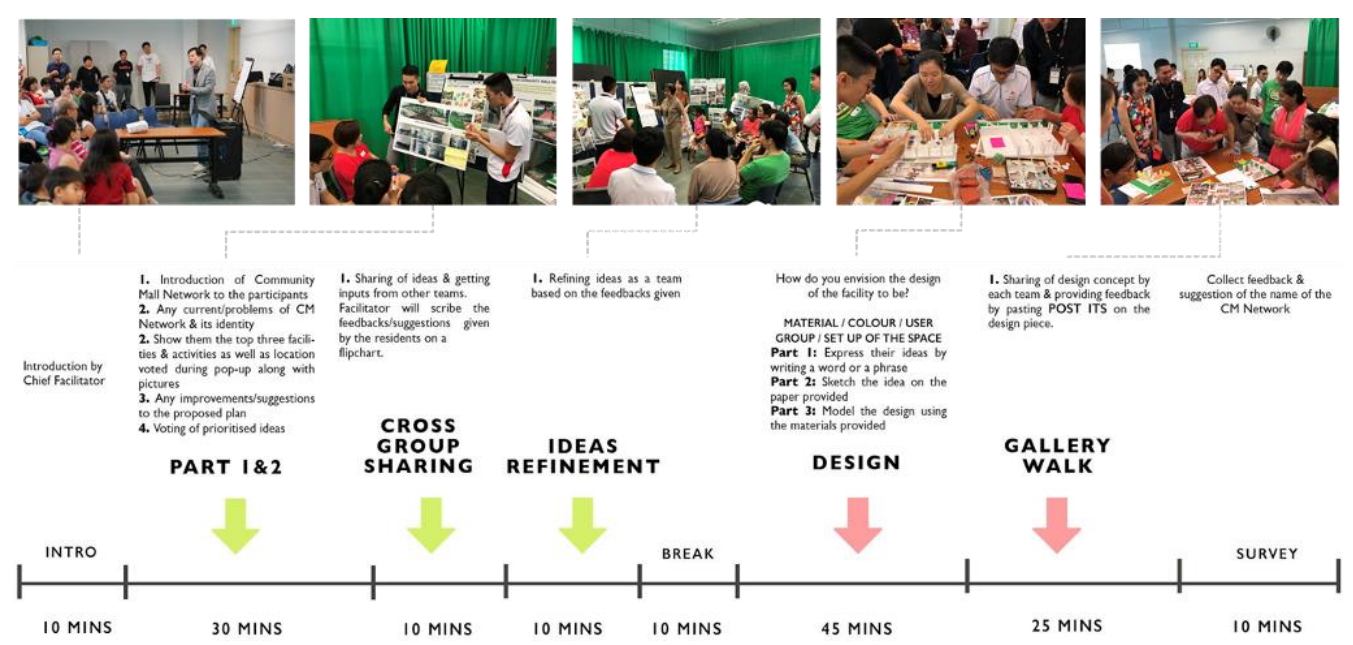

Figure 9. Process of the Ideation Workshop

Source: Workflow Designed by the Design Team from NUS and Photos Taken by the Author. 


\section{Presentation Strategies}

Besides visual aids of the possible design ingredients and brief introduction of previous participatory projects to guide the participants in design thinking process, the following co-generating methods were adopted in the Ideation Workshop to facilitate non-professional participants in design:

Post It notes were given to each participant to write down their concerns and questions and to discuss solutions during cross group sharing (Figure 10), so as to get the design brief by brainstorming and voting.

Picture Drawing and Collage Games evoked residents' awareness of community's current situation and possible activities and facilities in the future life. Each group was required to come out with a sketch of their design by collaging photos, drawings and descriptions on the A3 site picture (Figure 10), which provided significant foundation for subsequent steps.

Design Buffet provided the familiar setting of buffet meal to invite community stakeholders to design without prior training. ${ }^{17}$ Design ingredients (Figure 11) such as cut-out furniture catalogue, 3D base model in 1:30 and additional materials were prepared in a tray as "food" for participants to collect and carry out design by making models (Figure 12).
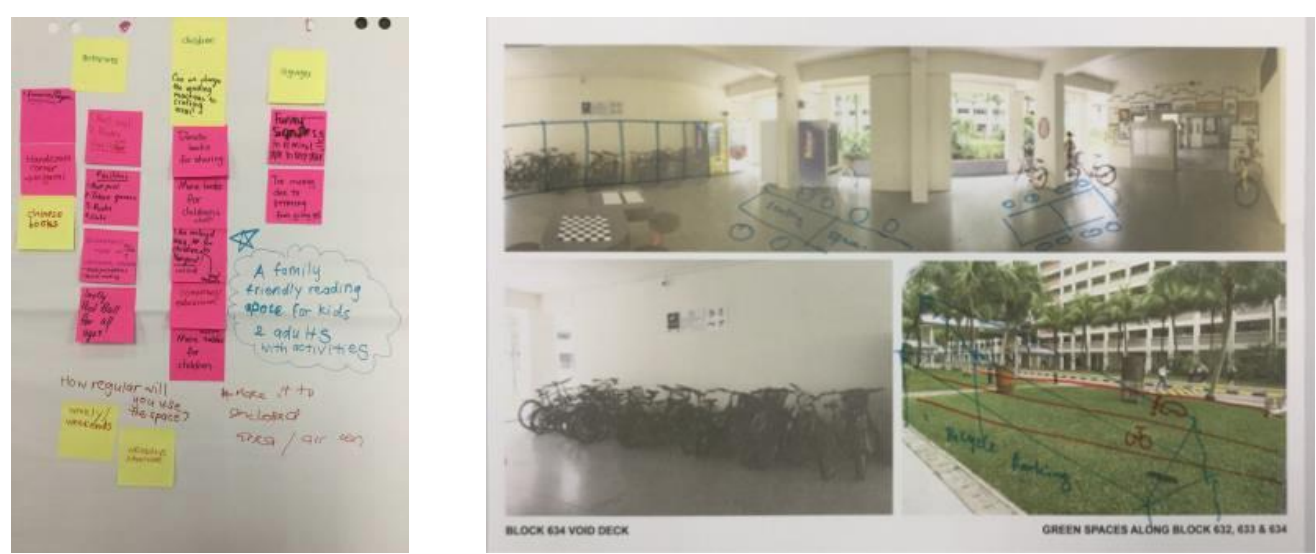

Figure 10. Brainstorming with Post It Notes (Left) and Picture Drawing and Collage Games to Visualize Design Ideas (Right)

Source: Presented by Residents Participating in the Ideation Workshop.
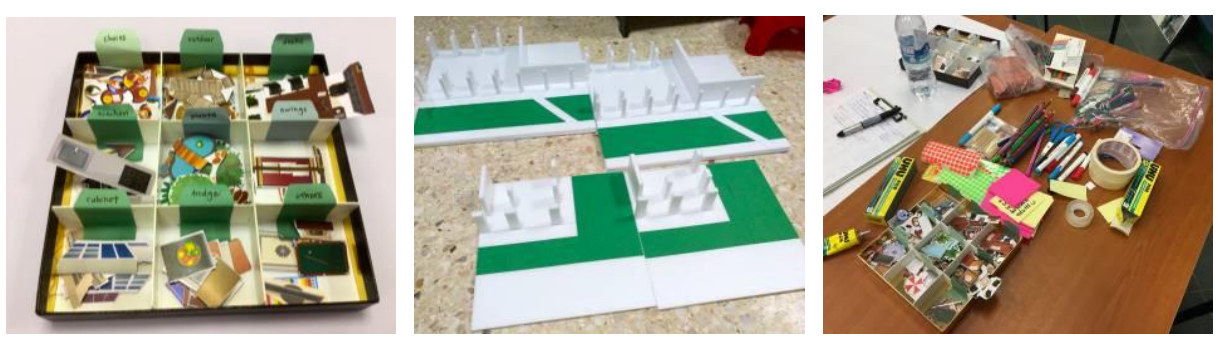

Figure 11. Design Ingredients Prepared for the Ideation Workshop

Source: Photos Taken by the Author.

17. Ibid, 178-181. 

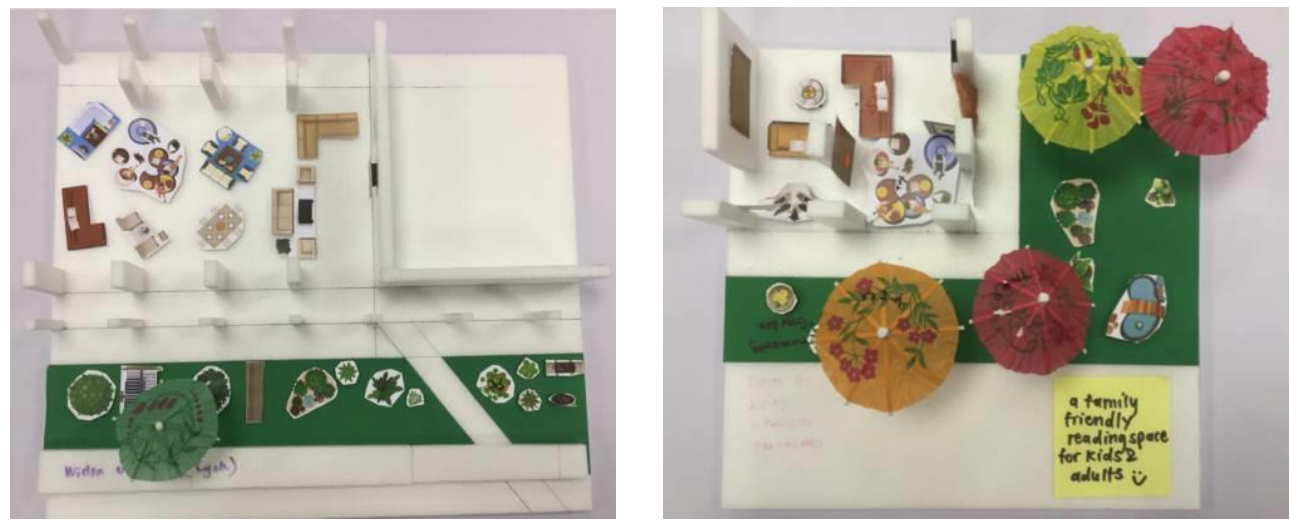

Figure 12. Models Made by the Residents in the Ideation Workshop

Source: Photos taken by the Author.
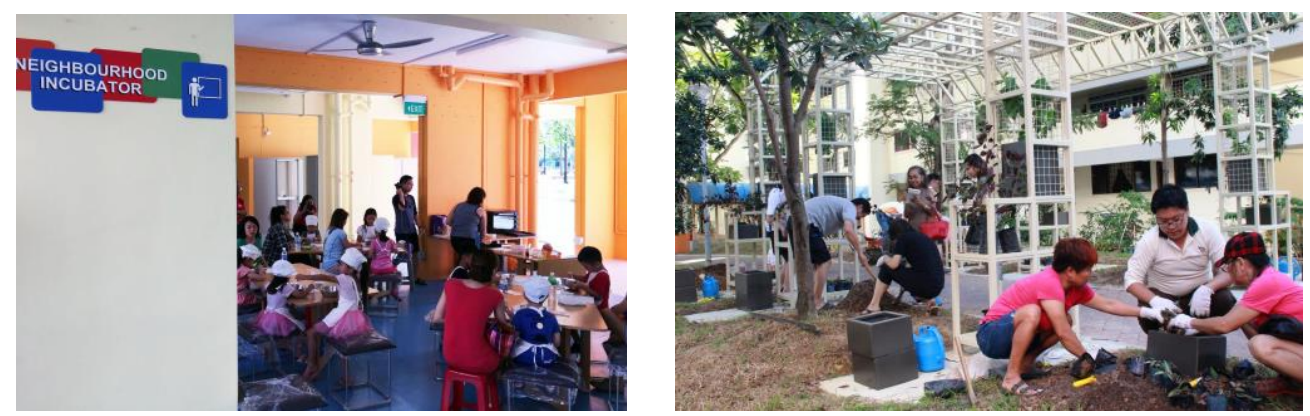

Figure 13. Neighbourhood Incubator and Social Linkway in "Hello Neighbour!" Source: CHO I S, KRIŽNIK B. Community-Based Urban Development Evolving Urban Paradigms in Singapore and Seoul[M]. Singapore: Springer Singapore, 2017: 138-139.

\section{Reflection of Singapore's Participatory Design}

\section{Practical Results and Effects}

Participatory design model in Singapore not only contributes to stimulating new space types, but also ensures that the design results meet the residents' needs. Firstly, two design typologies (Figure 13) are developed, practiced and concluded through a series of projects: one is Neighbourhood Incubator, a one-stop community hub to promote community activities and ground-up initiatives; the other is Social Linkway, which introduces communal functions and facilities to the transitory linkways to encourage residents to linger for social communication. Secondly, neighbourhood relationship has been strengthened not only during the design process but also in the daily use of the newly created spaces. For example, the design results of "Hello Neighbour!" registered around 200 visitors per day, spending an average of $13 \mathrm{~min}$ and with more than one in three users interacting with their neighbours, according to site surveys and interviews conducted by the NUS following the completion of the project in $2015 .^{18}$ Moreover, participatory

18. Cho and Kriznik, Community-Based Urban Development Evolving Urban Paradigms in Singapore and Seoul, 2017: 137. 
design programmes help to cultivate informal leader who would independently participate in the construction and improvement of the living environment in the future. For instance, in the past two years, several community gardens have been set up near Social Linkways by informal leaders who participated in "Hello Neighbour!" (Figure 14).

However, several particularities of the government-initiated top-down model are still questionable compared to bottom-up participatory design methods. Firstly, the design and construction cycle has been shortened due to relatively fixed time table, but the participation of residents is difficult to guarantee, especially when the resident participants are usually not a fixed group in different design stages. Secondly, as design typologies concluded from previous projects are often provided as reference for the residents, which may lead to a mind set and challenge the creativity and originality of the new design. Thirdly, the condition of short-term design results is unanticipated in the long run, because maintenance of them depends on the residents and the grassroots organizations in the long run.

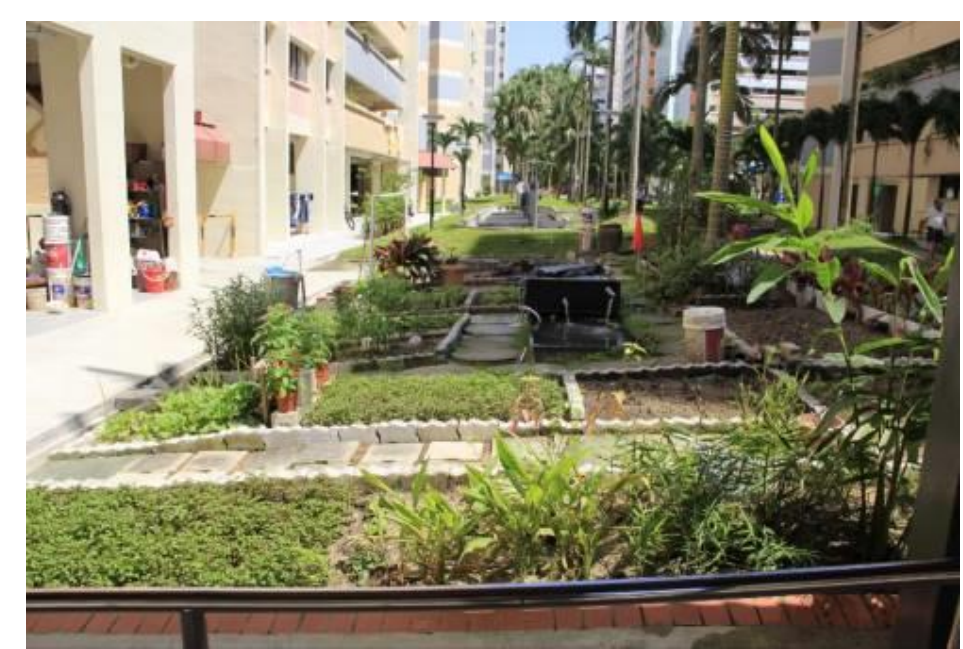

Figure 14. Community Garden Developed by Informal Leaders who participated in "Hello Neighbour!"

Source: Photo Taken by the Author.

Theoretical Significance and Enlightenment

Based on the perspectives of history and strategies, the historical continuity of public participation in shaping living environment is indicated: from selforganized operation, mutual-aided lifestyle and semi-public space, to multiple organizational support, participatory development process and community-based urban space. From this point, a community planning model based on interaction within system, environment and behavior could be concluded which targets at design process rather than physical environment (Figure 15). This model involves multiple fields such as urban planning, architecture design, economy and management, which requires involvement of professionals from different area as well as new department engaging in internal logic in interdisciplinary manner. 
However, the way to establish a communication mechanism to break the barriers of various disciplines is still the shortcoming of current research.

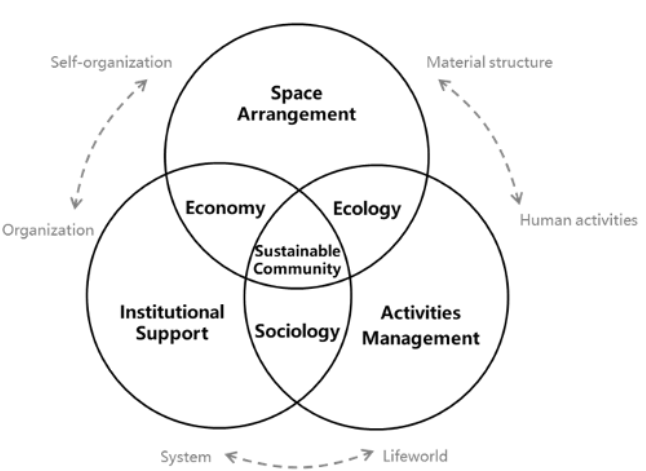

Figure 15. Organizational Structure (Left) and Planning Process (Right) Enlightened by Participatory Design

Source: Diagram Drawn by the Author.

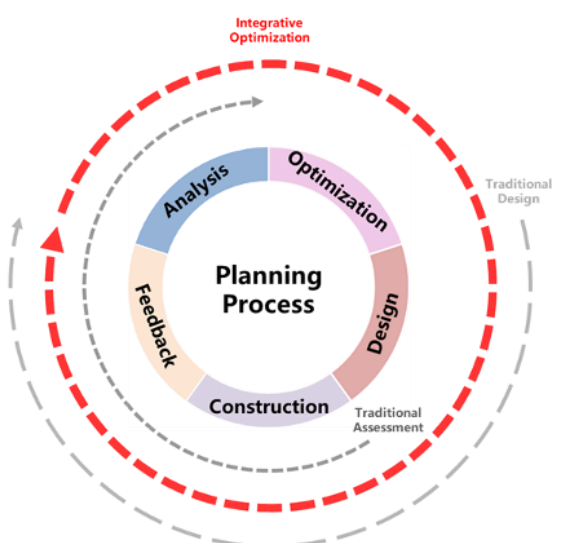

In addition, as the assessment from participants is gathered throughout the whole process and affects design results significantly, this trend could possibly develop the evaluation process from assessment model to optimization model (Figure 15), achieving self-development and self-renewal of the design process.

\section{Conclusions}

Based on development of public housing renewal in Singapore, this paper reveals the historical continuity of participatory design and proposed an optimization model which involves multiple fields and focuses on process: the transmission of a common concept (such as the kampong spirit) provides the basis for reaching consensus intersubjectively; a platform constructed by combining spontaneity and regulation shapes the process of collaborative operation; reference from case accumulation helps to guide non-professionals in designing.

It is worth mentioning that this model is not universal in practice considering the status of political and financial support and change of historical context, and there are still several limitations in current research: in terms of orgware, the power distribution of different participating groups is still unclear; in terms of software, as young people's leisure time is reduced, it is difficult to balance the time of participants in different ages; in terms of hardware, the contradiction between design simplification and construction mechanization and specialization remains to be discussed.

Based on achievement and enlightenment, there are also several issues for further discussion in practice: Firstly, it is essential to enhance the communication between the participation design process and the subsequent stages such as construction, operation and evaluation to reach participants' expectations and to form a cyclic design circulation; secondly, it is necessary to discuss the possibility 
to promote participatory design thinking into larger scale projects with more participants; Thirdly, it is challenging to localize Singapore's experience in other countries, considering that its urban-rural relationship is vastly different from the others.

\section{Acknowledgments}

Special thanks for supervision and related curriculum from Prof. Ho Puay Peng, Dr. Tan Beng Kiang and Prof. Cho Im Sik, and for the engagement and help from three design team members - Insyirah Bte Imran, Yan Zizhuo and Toh Choon Kiong Shawn - in Hillview @ Elias participatory project from the National University of Singapore. This research is funded by "Postgraduate Research \& Practice Innovation Program of Jiangsu Province (KYCX17_0106).

\section{Bibliography}

Cairns S., J. J. Jacobs, J. Yingying, R. Padawangi, S. Siddique and E. Tan. "Singapore's Void Decks." In Public Space in Urban Asia, 80-89. World Scientific Publishing Co. Pte. Ltd., 2014.

Carswell, A. T. The Encyclopedia of Housing. Thousand Oaks: SAGE Publications, 2012.

Cho, I. S. and B. Križnik. Community-Based Urban Development Evolving Urban Paradigms in Singapore and Seoul. Singapore: Springer Singapore, 2017.

Choe, A. F. C. "The Early Years of Nation-Building: Reflections on Singapore's Urban History." In World Scientific Series on Singapore's 50 Years of Nation-Building, 321. Singapore: World Scientific, 2016.

de la Peña, D., D. Jones Allen, R. T. Hester Jr., J. Hou, L. L. Lawson, M. J. McNally. Design as Democracy: Techniques for Collective Creativity. Washington, DC: Island Press, 2017.

Hassan, R. Families in Flats: A Study of Low-Income Families in Public Housing. Singapore: Singapore University Press, 1977.

Hee, L. and C. K. Heng. Transformations of Space: A Retrospective on Public Housing in Singapore Suburban Form: An International Perspective. London: Routledge, 2004, 140-142.

IAP2's Public Participation Spectrum. Louisville: International Association for Public Participation, 2014. www.iap2.org/resource/resmgr/foundations_course/IAP2_P2_ Spectrum_FINAL.pdf. [Accessed 6/7/2018].

Lim, W. S. W. Public Space in Urban Asia. Singapore: World Scientific Publishing Co., 2014.

Naidu, P. and J. Lua. Spot on Facilitation. $2^{\text {nd }}$ Edition. Singapore: Candid Creation Publishing, 2015.

Neighbourhood Renewal Programme - NRP. Singapore: Housing \& Development Board, 2017. https://www.hdb.gov.sg/cs/infoweb/residential/living-in-an-hdb-flat/sers-andupgrading-programmes/neighbourhood-renewal-programme-nrp\&rendermode=pre view. [Accessed 28/6/2018-06-28].

Sanoff, H. Community Participation Methods in Design and Planning. Hoboken: John Wiley \& Sons, 1999.

Sanoff, H. "Multiple Views of Participatory Design." Focus 8, no. 1 (2011): 11-21. 
Stanilov, K. and B. C. Scheer. Suburban Form: An International Perspective. New York: Routledge, 2004, 127-147.

Tan, K. P. "Public Engagement: The Gap between Rhetoric and Practice." In Ethos. Edited by A. Pang and S. Ng. Singapore: Centre for Governance and Leadership, Civil Service College, 2012.

Tang, K. F. Kampong Days: Village Life and Times in Singapore Revisited. Singapore: National Archives, 1993.

Wates, N. The Community Planning Handbook. $2^{\text {nd }}$ Edition. London: Routledge, 2014. 
